\title{
A Comparative Study on the English and French Translated Edition of A Dream of Red Mansions
}

\author{
Zhe Yuan ${ }^{1, A}$; Dan Zhou, ${ }^{1, b}$ \\ ${ }^{1}$ Wuhan Textile University, Wuhan, 430073, China \\ aemail: pauline_2005@163.com; 'bhoudan@wtu.edu.cn
}

Keywords: A Dream of Red Mansions, English, French.

\begin{abstract}
A Dream of Red Mansions is one of the most famous classics in Chinese history, which involves Chinese culture in every regard, so it is more than a literature, appreciated as the encyclopaedia of Chinese culture. As for the English translated edition of A Dream of Red Mansions, there exist nine versions in total, among which Yang \& Gladys' and Hawks' versions are the most influential ones. The translation studies on this classic novel has flourished and expanded long since, yet comparative studies on the English and French translated edition of A Dream of Red Mansions have not been touched upon. Therefore, this paper selected two typical translated versions to make a comparison.
\end{abstract}

\section{Introduction}

As for the English translated edition of A Dream of Red Mansions, there exist nine versions in total, among which Yang \& Gladys' and Hawks' versions are the most influential ones. (Hawks translates the title as The Story of the Stone.) [1]As for the French translated edition, it appeared in 1921, but was merely abridged translation. [2]The most influential one is translated by French-Chinese translator Li Zhihua and his wife, proofread by sinologist Andre d'Hormon in 1982, with the title Le Rêve dans le pavillon rouge.

The research objects of this paper are Yang \& Gladys’ A Dream of Red Mansions and Li \& Yage's Le Rêve dans le pavillon rouge. [3] The original version has numerous characters and elaborate structures, all-embracing with abundant Chinese culture-loaded words, proverbs, allusions and even poetry, so many translators are deterred. Nevertheless, the translators of these two editions thoroughly fulfil the hard work through strategies of excellence, rigorousness and perseverance. These two editions converged with professional ethics are exceptional English and French versions.

\section{The authors and compilation course of two editions}

This paper chose the comparable objects on the one hand because both of the editions are translated by a Chinese and his foreign wife, which means that they both must share some similar experience in the course of translation. On the other hand, the publication time of the two is approximate; the English edition was published in 1980, while the French one was in 1981.

The publication of the three-volume English version of A Dream of Red Mansions has brought great reputation to Yang and his wife, and moreover, an accumulation of their social status. According to Biography of Yang Xianyi written by Lei Yin, the couple had a division of work; Yang was in charge of the first draft, and Gladys modified and polished the draft. There was a tacit cooperation between them. However, Gladys spent three times as much time as Yang, because she needed to not only read Yang's first draft, but also discuss with her husband and hammer out some questions through comparing to the original Chinese version. 
The French edition was first published by Gallimard in 1981, which is unique for including all the poetry and songs of the classic novel. The author Li Zhihua said that translation is a work from one language to another; a good translation deserves proficient in both the source language and the target language. [4]Generally speaking, the goal can be attained though the cooperation of masters in the source and those in the target language. On account of this, $\mathrm{Li}$, his wife $\mathrm{Ya}$ Ge and supervisor Andre d'Hormon cooperated for ten years. However, in the course of polishing the 50th chapter, Andre d'Hormon died from disease. Later the couple spent another 17 years to modify and polish their translation. Therefore, the French edition Le Rêve dans le pavillon rouge was started in 1954 and eventually came out in 1981.

It turns out that these two editions are based on the cooperation of the couple, by means of which the translation can sufficiently express the intention of the source language and in the meantime follow the reading habits of the target language to a large extent.

\section{Translation theories and strategies of two editions}

Chinese enlightment thinker Yan Fu demonstrated in the introductory remarks of his work Evolution and Ethics that there are three difficult points in translation: faithfulness, expressiveness and elegance. [5]To be faithful to the source language is difficult, but without fluent expression, correct comprehension of the work will not be digested by the target language users. Therefore, expressiveness needs to be think highly of as well.

In 2009, Yang was modest enough to say that he was not skilled in translation theory at the ceremony of Translation and Culture Lifetime Achievement Award, and he started his translation in accordance with Yan Fu's comments on translation. He maintains that translators should strive for faithfulness and expressiveness, and elegance is usually a higher requirement. He admitted that he translated with the guidance of these three points. As for the translation strategies, Yang adheres to the faithfulness to original work, but in reference to culture-related translation, he mainly adopts foreignizing strategies to make the translation understood. With the combination of literal and liberal translation, he in the meanwhile, adds a mass of endnotes and footnotes to his translation for the sake of smooth comprehension of readers. To take the translation of characters' names as an example, all of the names in A Dream of Red Mansions are translated through transliteration (Pao-yu, Tai-yu). [6] However, the nicknames and names of the visionary characters are translated with the method of liberal translation (the Goddess of Disenchantment, Stupid Tyrant). For the translation of some idioms in the work, Yang chooses strategies according to the actual situation. For example, "Foes are fated to meet" and "Strike while the iron is hot", which are both vivid and appropriate.

With regard to the French edition translated by Li and Ya, the comments from critics are as many and fabulous as the imperial palace in the eighteenth century in western countries. [7]Chinese critics point out that the distinctive features of this translation is the faithfulness to the original work, which is not only the paramount principle in translation field in China, but also the rule that the couple strictly observed in the course of translation. By and large, the French edition combines literal and liberal translation strategies. Most of the texts are translated literally, but for some duplicated names, the couple translate them liberally (bouffé de parfum, Jia le Politique). For the translation of some idioms in the work, they flexibly select strategies. It needs to be emphasized that their liberal translation is not confined to the words of the source language, but they attempt to seek for the corresponding expressions for the target language to make their translation more acceptable. For example, “donner des pattes au serpent”. 


\section{The evaluation of two editions}

"Since 1978, Yang and Gladys' A Dream of Red Mansions has been published by Beijing Foreign Language Press. The entire book has three volumes, big-paper edition and blue clothbound. There are even several colourful illustrations in it drawn by famous painter Dai Dunbang, increasing joyfulness of the novel. The evaluation of this translation is not unified, but two points can be affirmed: firstly, it is the earliest cover-to-cover translation in the world (till 1980); secondly, the translation is faithful to the original work (Although there appear several faults which are inevitable.) This book started in 1978, the translation and prepublication was during the Great Cultural Revolution, so it was unavoidably affected.”

“In 1981, Li Zhihua and Ya Ge’s Le Rêve dans le pavillon rouge was published. The translation has once made a stir in European literary circle, which is regarded as a great event in 1981. At that time, bookstores in Paris and the surroundings displayed this French edition in the remarkable places. Some bookstores even sent invitation to $\mathrm{Li}$, Chinese literature lovers and sinologists to their reading clubs to introduce this masterpiece.”

It shows that these two editions with different place of publication receive different evaluations, and they also have different influences. The English edition was translated and published in China, which was closely related to the political and economic situation at that time. Nevertheless, the French edition was translated and published in France, which had an immediate and direct influence on the French readers, so the comments on this work, was immediate as well.

\section{The significance of two editions}

These two editions are faithful enough to the original work with graceful language and fluent writing. Both of them are exceptional translation which makes great contribution to the spreading of our classics to western countries. Foreign readers can appreciate Chinese literature owing to their devotion. Furthermore, it is possible for the foreign people to start to study of A Dream of Red Mansions.

\section{Conclusion}

"Redology” (study of A Dream of Red Mansions) in China is booming nowadays, but the translation studies on it are not comparable. In October of 2002, NKU (Nankai University) and CTJ (Chinese Translators Journal) held a translation seminar on A Dream of Red Mansions. In the seminar, the English translation studies were the overwhelming majority and without a paper on French translation. Wang Hongyin pointed out in the final report that translation studies on French and other languages need to be further developed and mutually connected with English. The multilingual and interdisciplinary research is what we aim to today. I hope this paper can be a start and more scholars dig into this field.

\section{Acknowledgements}

*This paper is the research project of humanities and social science in education department of Hubei, "The comparative study on the English and French translated edition of A Dream of Red Mansions " (project number: 17Q090) and the educational program in Hubei (project number: 2016GB036) 


\section{References}

[1]Chen H. W., Fan J., The Translation of Hong Lou Meng into English: A Descriptive Study[J]. Chinese Translators Journal. 2003 (5).

[2]Li Z. H., Li J., Translation Stories in Lyon[M]. Commercial Press. 2005Qian Linsen, A Dream of Red Mansions in France[J]. Social Science Front. 1984 (1).

[3]Lei Yin, Biography of Yang Xianyi[M]. Ming Pao Publications Ltd. 2007

[4]Li Shiwei, The Translation Strategies of French version of The Dream of the Red Chamber[J]. Study Commentary of A Dream of Red Mansions. 2013.

[5]Han Zhonghua, Comments on Yang\&Gladys' English Version of A Dream of Red Mansions[J]. Study Commentary of A Dream of Red Mansions. 1986 (3).

[6]Wang Hongyin, Comments on Proceedings on Translation Studies of A Dream of Red Mansions[M]. Nankai University Press. 2004.

[7]Jiang Qihuang, Redology in the West[M]. Elephant Press. 2005. 